\title{
El trabajo en equipo
}

«Una de las primeras lecciones que un ejecutivo aprende mientras progresa hacia las alturas de la empresa es lo poco que puede seguir confiando sólo en su propia inteligencia. Cuanto más alto es el nivel que alcanza un individuo en la organización más evidente resulta que un directivo es bueno en la medida que lo es el grupo que le rodea."

I. S. SHAPIRO,

La tercera revolución americana

SUMARIO: I. INTRODUCCION. II. LA NECESIDAD DEL TRABAJO EN EQUIPO. La toma de decisiones. Las ventajas de la participación. La libertad de los actores. III. LIDERAZGO. Modelo del continuo autocrático-democrático. El liderazgo situacional: La madurez de los subordinados. El comportamiento del directivo. Aplicación del modelo. IV. COMUNICACION. Variables en relación con el emisor. Variables en relación con el receptor. Estilos cognitivo-profesionales: dinámicos, reflexivos, perceptivos, intuitivos. La adaptación. Análisis Transaccional: Los estados del Yo. Análisis funcional. Las transacciones. Comportamiento profesional.

\section{INTRODUCCION $\left({ }^{*}\right)$}

En este trabajo vamos a tratar de algunas técnicas que pueden ayudarnos a dirigir mejor los equipos, a superar las barreras en la comunicación y a minimizar los conflictos interpersonales.

Estas técnicas son necesarias porque el funcionamiento de los equipos no es sencillo. De hecho, para que se pueda hablar propiamente de equipo es preciso que se den una serie de circunstancias (1) que lo configuren como tal, más allá de los límites del simple grupo:

- En primer lugar, el número de miembros ha de ser relativamente reducido, ya que de otro modo el conjunto resulta inmanejable y la eficacia se ve comprometida.

(*) Mi agradecimiento a Alberto Chueca Mora tanto por sus comentarios como por su ayuda en la búsqueda de fuentes bibliográficas. p. 6.

(1) MuCCHIELLL, Roger: Le travail en equipe (5." edición). Les editions ESF, París, 1989, 
- En segundo término, deben darse unos lazos interpersonales cualitativos. Un equipo es una red de lazos vivos, en cuyos miembros existe una cierta conciencia de pertenencia y una cierta forma de cultura común. En él no hay sólo una adhesión, sino una aceptación y una voluntad de adhesión.

- Por otra parte, debe existir una implicación personal que constituya un compromiso, una comunidad de acción; lo que no significa identidad de acción, sino más bien complementariedad en la integración.

- El objetivo colectivo es otro requisito para la existencia de equipo. Este no puede funcionar como tal sin una intención común de caminar hacia una meta.

- En contrapartida, existen límites y obligaciones que, aunque no sean percibidos exteriormente, se consideran implícitos para los miembros del equipo, que deben renunciar a un cierto grado de libertad, aceptar una táctica común, etc., para alcanzar el objetivo común.

- Finalmente podríamos mencionar la organización, que será variable según el tipo de acción, los objetivos y el contexto.

Lograr todo lo anterior constituye una forma superior de hacer frente a los problemas que se les plantean a nuestras organizaciones y de alcanzar los objetivos que persiguen. Pero es evidente que no resulta posible lograrlo de un día para otro, aunque, por el contrario, sí lo sea el perderlo en tan corto plazo en el supuesto de que se haya logrado previamente.

En este trabajo haremos inicialmente unas reflexiones sobre la necesidad del trabajo en equipo en las organizaciones actuales como respuesta a una triple exigencia: su propia complejidad, las necesidades de los propios miembros de las mismas y de las organizaciones cuyo objetivo es solucionar problemas sociales. A continuación, ya en el terreno de las técnicas propiamente dichas, nos referiremos a dos aspectos esenciales en el funcionamiento de los equipos: el liderazgo y la comunicación.

En el caso del liderazgo desarrollaremos dos modelos, el continuo autocrático-democrático y el liderazgo situacional, como instrumentos que posibilitan una dirección de los equipos y de sus miembros ajustada a las necesidades de éstos, del entorno y del trabajo a llevar a cabo.

En cuanto a la comunicación, trataremos de los estilos cognitivoprofesionales y del Análisis Transaccional. Ambas técnicas proporcionan un bagaje suficiente para mejorar la eficacia de la comunicación intragrupal y reducir el riesgo de conflictos interpersonales y profesionales o minimizarlos en el caso de que se produzcan.

Estas técnicas, como tantas otras, son instrumentos que pueden hacer más fácil el cohesionar los grupos de trabajo para convertirlos en 
equipos que reúnan las características que hemos enumerado más arriba. Pero no son fórmulas mágicas, hay que saber utilizarlas y no son polivalentes. Para cada tarea, como señala el propio Paul HERSEY, teórico del liderazgo situacional que luego veremos, existe un útil que hay que conocer y saber manejar. Por otra parte, en muchas ocasiones la simple utilización de un instrumento aparentemente adecuado no es garantía de éxito, ya que pueden entrar en funcionamiento determinadas circunstancias que reduzcan su eficacia o que aconsejen su cambio por otro más potente o menos agresivo para el entorno.

\section{LA NECESIDAD DEL TRABAJO EN EQUIPO}

\section{La toma de decisiones}

Dirigir, entre otras cosas, es obtener resultados con personas ajenas. Como consecuencia de ello los directivos de distinto nivel en sus respectivas organizaciones se enfrentan a diario al dilema de cómo tomar las decisiones: en solitario o con la participación de esas otras personas, porque, en última instancia, como indica Peter F. DRUCKER, todo lo que hace un directivo, lo hace tomando decisiones.

El método clásico de toma de decisiones dista mucho de ser realista. De acuerdo con él, el proceso se ordena en cuatro fases perfectamente diferenciadas: en la primera el responsable de la decisión establece claramente los términos del problema planteado o necesidad existente; en la segunda identifica todas las posibles alternativas que puedan dar solución al problema o satisfacción a la necesidad; en la tercera le corresponde hacer la valoración de las distintas alternativas existentes para clasificarlas según su idoneidad, en atención a sus ventajas, inconvenientes, etc.; finalmente, en la cuarta se lleva a cabo la opción por una de ellas y posteriormente se pasa a ponerla en práctica.

Efectivamente, éste es el método científico de toma de decisiones, pero como ya hemos avanzado, la realidad es algo más compleja. En primer lugar, los individuos difícilmente son capaces por sí solos de formular los problemas claramente, además de por sus propias limitaciones porque carecen de toda la información necesaria para hacerlo. Por otra parte, es prácticamente imposible que un sujeto, por las mismas razones, identifique todas las alternativas existentes, pero además le resulta extremadamente difícil valorarlas en términos objetivos. Es decir, existe un grado de riesgo variable en la toma de decisiones, por la posibilidad de errores personales en la valoración, por la insuficiencia de los datos disponibles y finalmente por la colisión entre los valores y objetivos personales y los de la organización. 
Todo ello puso ya hace años en cuestión la teoría clásica de la toma de decisiones elaborada por los economistas para optimizar el rendimiento de las personas, pero al mismo tiempo ha servido para reforzar la importancia del trabajo en grupo, confirmándose la superioridad de los equipos de trabajo sobre la actuación individual, a partir de la demostración de que la suma de los esfuerzos de varias personas en un grupo es superior a la suma de los esfuerzos de esas mismas personas actuando por separado.

\section{Las ventajas de la participación}

No es preciso que nos remontemos al siglo vi en el que ya San Benito recomendaba a los abades benedictinos que cuando tuvieran ante sí un problema grave, antes de tomar una decisión, convocasen a toda la comunidad para escuchar su opinión, incluso la de los recién llegados, porque «en numerosas ocasiones Dios revela lo que es mejor a los más jóvenes» (2). Pero sí queremos subrayar que a lo largo del siglo $\mathrm{XX}$, desde la dirección científica de TAYLOR hasta la Teoria $Z$ de OUCHI, pasando por los trabajos de MAYO en Hawtorne o las aportaciones de LEWIS, LIKERT, McGREgOR, LEAVITT, HERSEY, BLANCHARD e ISHIKAWA, entre otros muchos, la producción teórica y los estudios empíricos sobre la dirección de los colaboradores en las organizaciones de diferente tipo han sido muy abundantes y de importancia, habiéndose consolidado la idea de que, en términos generales, la participación de las personas en el proceso de toma de decisiones resulta beneficiosa para la consecución de los objetivos.

Sentado este principio, una vez que el taylorismo (división rígida entre directivos-pensadores-decisores y subordinados-ejecutores) ha quedado definitivamente superado, la cuestión hoy se centra más bien sobre el grado y características de esa participación.

Por otra parte, la complejidad socioeconómica y tecnológica de la sociedad actual ha provocado una fuerte interdependencia entre los especialistas de las distintas áreas del conocimiento, de tal modo que los ingenieros y economistas necesitan, ineludiblemente, consultar a los expertos en Derecho las implicaciones legales de una determinada actividad; a su vez, estos últimos, para llevar a cabo eficientemente su trabajo, necesitan el apoyo de los informáticos que les posibilitan mejorar el tratamiento y recuperación de la información jurídica; y, en otras ocasiones, unos u otros necesitan los servicios de los sociológos para prever las reacciones sociales ante una posible medida que se desea adoptar.

(2) Citado por Vroom, Víctor H., y Jago, Arthur G.: El nuevo liderazgo. Dirección de la participación en las organizaciones, Ediciones Díaz de Santos, Madrid, 1990. 
A lo anterior hay que unir la profunda evolución a que se han visto sometidas las estructuras organizativas, que se han ido transformando tanto como consecuencia de las presiones del entorno como de las propias expectativas de sus miembros. Hemos pasado del predominio de las organizaciones piramidales, basadas en el principio de jerarquía y en el protagonismo del jefe, a las organizaciones estructuradas en forma de red, en las que la cualidad más valorada es la información y el protagonismo corresponde al equipo de trabajo. En estas últimas la forma natural de trabajo es el equipo, por considerarse que es la mejor manera de aglutinar los conocimientos, las técnicas y la información precisos para dar satisfacción a las necesidades existentes y solución a los problemas planteados (3).

Además, la estructura en red y el equipo como forma de trabajo dominante permiten a las organizaciones reaccionar con mucha mayor flexibilidad y rapidez ante los cambios que se producen en su entorno (4), frente a las rigideces y lentitud que caracterizan la actuación de otros modelos organizativos.

\section{La libertad de los actores}

El estudio y clasificación de las organizaciones se ha llevado a cabo, de forma ya clásica, en base a la existencia de los siguientes rasgos determinantes (5):

- División de tareas.

- Distribución de roles.

- Sistema de autoridad.

- Sistema de comunicaciones.

- Sistema de contribución-retribución.

El segundo de estos rasgos - la distribución de roles- puede sernos útil para comprender cómo las formas de trabajo y la toma de decisiones han ido evolucionando en el seno de las organizaciones como consecuencia, entre otras razones, de la necesidad de dar satisfacción a las expectativas de sus miembros en estas materias.

La teoría conocida como análisis estratégico (6) presta una atención especial a la interpretación de los papeles en la organización. Según

(3) NiCOLAS, Pierre, y TuRBE, Jacques: Gestion des reunions, Les Editions d'Organisation, París, 1987.

(4) Para un análisis en profundidad de la incidencia del entorno sobre las organizaciones: Ansoff, H. Igor: La dirección y su actitud ante el entorno, Ediciones Deusto, Bilbao, 1985.

(5) Bernoux, Philippe: La sociologie des organisations, Editions du Seuil, París, 1985.

(6) Crozier, Michel, y FriedberG, Erhard: L'acteur et le sistème. Les contraintes de l'action collective, Editions du Seuil, París, 1977. 
Crozier y FriedberG, cada miembro de la organización ve cómo, en virtud del primero de los rasgos constitutivos que hemos enunciado, se le atribuye un rol, más o menos definido. Pero el término rol, o papel, ya nos sugiere la idea de un actor, de tal modo que el desempeño del papel que le ha sido atribuido puede llevarse a cabo de una manera particular, que responda a las propias percepciones e inclinaciones del intérprete. Dicho en otras palabras, según esta concepción, los miembros de una organización son como actores que tienen la posibilidad, y a veces el encargo, de interpretar de manera distinta un papel que ya se ha desarrollado de otra forma que no ha resultado satisfactoria, que ya no corresponde a la situación actual o, simplemente, que se percibe de otto modo a como se venía haciendo: «Una situación organizacional dada jamás constriñe totalmente a un actor. Este guarda siempre un margen de libertad y de negociación. Gracias a este margen de libertad (que es una fuerte de incertidumbre para sus colegas y para la organización en su conjunto), cada actor dispone así de poder sobre los otros actores (...)» (7).

En esta y otras teorías, la puesta del acento en el protagonismo y en la libertad de los miembros de la organización obedece entre otros factores a la relativización de las posibilidades de un comportamiento estrictamente racional y planificado a priori basado en planteamientos sistémicos. Siguiendo de nuevo a DRUCKER diremos que toda decisión es una elección entre varias posibilidades y raramente una opción entre lo correcto y lo incorrecto: «La decisión efectiva no emana, como muchos textos sobre la toma de decisiones proclaman, de un consenso sobre los hechos. El entendimiento en que se apoya toda decisión correcta es fruto del choque y conflicto de opiniones divergentes y de un serio análisis de alternativas opuestas» (8).

Con todo lo anterior hemos pretendido justificar y explicar nuestra convicción acerca de la necesidad y la superioridad de los equipos sobre el trabajo individual y llamar la atención sobre la ineludible necesidad de incorporarlos como forma de trabajo habitual de las organizaciones públicas, incluidas las de corte más tradicional y con actividades estrechamente vinculadas a la potestas, para dar mejor 'satisfacción a las necesidades que interna y externamente tenemos planteadas.

\section{LIDERAZGO}

- Inicialmente dijimos que dirigir es obtener resultados a través de otras personas. Ahora debemos añadir que la clave de una buena di-

(7) Crozier y Friedberg: op. cit., p. 91.

(8) DruCKer, Peter F.: El ejeculivo eficaz, EDHASA, México, 1989, p. 157. 
rección es el liderazgo. En las últimas décadas en el ámbito de la dirección se ha profundizado mucho sobre el concepto de liderazgo. Finalmente parece existir un cierto consenso (BORMAN, HUSE, BOWDITCH, ROBBINS...) en entender por liderazgo la capacidad de influir en un grupo determinado para la obtención de metas (9). Asimismo se ha establecido la diferenciación entre autoridad formal y liderazgo propiamente dicho, en la medida en que, como señala MinTzBERG (10), aquélla otorga, en virtud del organigrama, un gran poder potencial a los directivos, que éstos sólo transforman en poder real, en mayor o menor medida, mediante el ejercicio de su propia capacidad de liderazgo para influir sobre las personas. Igualmente se acepta, al llevar a sus últimas consecuencias la idea anterior, que puede existir liderazgo por fuera de la estructura formal de la organización, es decir, que puede existir liderazgo con o sin nombramiento formal.

Conforme la teoría sobre las organizaciones ha ido progresando, en los estudios sobre liderazgo se han sucedido diversos enfoques que se agrupan en tres grandes bloques: la teoría de rasgos, que se refiere a los rasgos comunes que caracterizarían universalmente la personalidad de los líderes (inteligencia, carisma, entusiasmo, valor, etc.); la teoría del comportamiento, que profundiza sobre el estudio de las conductas para identificar los aspectos determinantes de su comportamiento (estructuración del rol propio y de sus subordinados, relaciones interpersonales, etc.), y, por último, los modelos de contingencia que se centran en identificar los aspectos de la realidad que condicionan la actuación de los dirigentes (la cultura, los superiores, el entorno, el clima organizacional, etc.).

Los dos primeros enfoques se consideran hoy día superados por ser excesivamente rígidos y simplistas, por lo que a continuación nos referiremos únicamente a dos de las teorías de contingencia: sencilla la primera, el modelo del continuo autocrático-democrático, y algo más compleja la segunda, la teoría del liderazgo situacional.

\section{MODELO DEL CONTINUO AUTOCRÁTICO-DEMOCRÁTICO}

Este modelo, elaborado por TANNENBAUM (11), parte de la idea de que los estilos de mando autocrático y democrático no sólo son dos posturas contrapuestas, sino que constituyen los extremos de otras posturas diferentes intermedias que pueden darse a lo largo de un conti-

(9) RobBins, Stephen P.: Comportamiento organizacional, Prentice-Hall, México, 1990, p. 244.

(10) MintzBERG, Henry: La naturaleza del trabajo directivo, Ariel, Barcelona, 1983, p. 95.

(11) TANNENBAUM, Robert, y SCHMIDT, Warren: «How to choose a leadership pattern", en Harvard Bussines Review, marzo-abril, 1958. 
nuo. Los extremos, como se ve en el gráfico, operan de tal manera que existe una vinculación entre ellos como si se tratara de un juego de suma cero: a mayor autoridad del directivo menor ejercicio de la libertad de los subordinados y el contrario.

Por su sencillez y claridad el modelo no requiere explicación. Sin embargo, sí conviene llamar la atención acerca de que, independientemente del grado de libertad de que dispongan los subordinados, el directivo nunca pierde la iniciativa. La mantiene tanto cuando actúa en el extremo autoritario del modelo, limitándose a comunicar la decisión que previamente ha adoptado en solitario, como cuando, en el extremo opuesto, transmite a sus colaboradores los límites establecidos por una autoridad superior para, a continuación, concederles libertad de actuación dentro de las reglas de juego expuestas y que han sido fijadas por alguien exterior al propio equipo.

MODELO DEL CONTINUO AUTOCRATICO-DEMOCRATKO titement Rumb

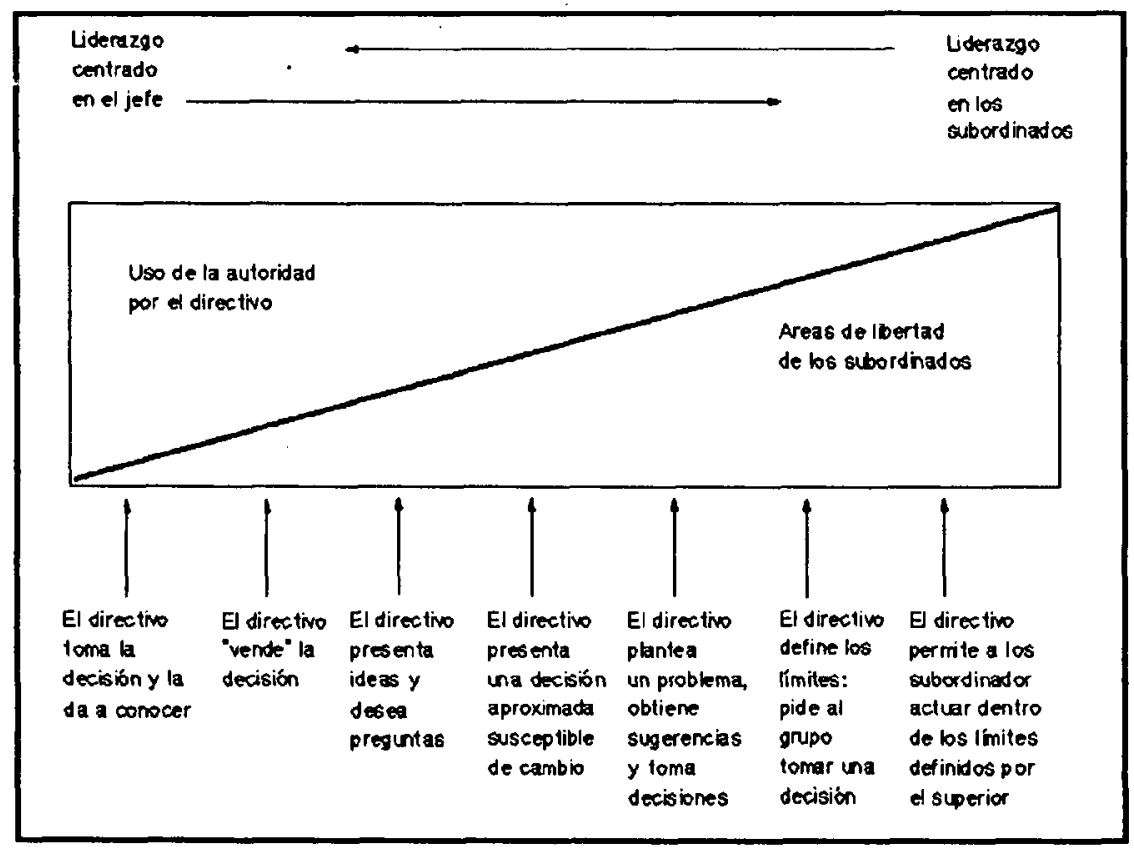

Los estudios empíricos que se han llevado a cabo para comprobar los efectos de los distintos estilos señalan que los de carácter participativo son claramente superiores a los de indole autoritaria en cuanto inciden positivamente sobre la satisfacción de los subordinados, sin que se encuentre claramente establecida una relación positiva entre participación y mayor productividad (12).

(12) RobBins, Stephen P.: op. cit., pp. 251 y ss. 
Otros trabajos experimentales realizados con niños habían mostrado anteriormente que, globalmente, los grupos con liderazgos democráticos son superiores a los autoritarios y sus líderes más populares. No obstante, cuando el líder autoritario se encuentra presente la productividad es superior en su grupo, si bien baja automática y significativamente en su ausencia, en tanto que se mantiene en el caso de los grupos dirigidos democráticamente que, por otra parte, tienen una mayor cohesión interna.

En cualquier caso, como señalan TANNENBAUM y SCHMIDT, de acuerdo con los principios del comportamiento contingente, la idoneidad de uno u otro estilo vendrá determinada por la combinación de distintos factores, que ellos agrupan en tres grandes bloques de fuerzas: las fuerzas de líder, entre las que habría que incluir aspectos tales como un sistema de valores, la seguridad en sí mismo o su confianza en el grupo; las fuerzas de los subordinados; relativas a la cualificación técnica, la iniciativa y capacidad de participación, así como la madurez en la toma de decisiones, y finalmente, el tercer bloque, concerniente a las fuerzas de la situación, incluiría el grado de urgencia existente para tomar la decisión, las características de la propia organización y el tipo de problema planteado.

En conclusión, no hay, en sí mismo, un estilo mejor que otro. La conveniencia de utilizar uno de ellos vendrá determinada por las circunstancias que rodean al directivo, público en nuestro caso, en un momento dado, así como por su propia situación en ese momento. Posteriormente, el cambio de circunstancias podrá aconsejar la transición a otro estilo más acorde.

Esto es algo que todos los que han ocupado puestos de responsabilidad en la Administración han podido experimentar con ocasión del paso de un puesto de trabajo a otro. En la organización correspondiente al puesto que se venía desempeñando anteriormente ya se dispondría de un equipo de personas conocedoras de su trabajo e identificadas con los criterios de actuación de su directivo, lo que permitiría a éste un estilo de trabajo más democrático y participativo, apoyado en las sugerencias de sus colaboradores. Probablemente en el nuevo puesto la situación será diferente, ya que aunque las personas que allí encuentre el directivo conozcan bien su trabajo, tal y como lo venían haciendo hasta el momento, se verán obligados a introducir modificaciones como consecuencia de las innovaciones y nuevos proyectos lanzados por aquél. Esta circunstancia le llevará, sin duda, junto con el desconocimiento que inicialmente tendrá sobre las aptitudes y actitudes de sus nuevos colaboradores, a utilizar un estilo más personalista y menos participativo, en los primeros momentos al menos. Así, presentará sus decisiones solicitando únicamente opiniones sobre las mismas que le permitan ir conociendo a los colaboradores y medir su 
potencial. Transcurrido un cierto tiempo, ya articulado el grupo en torno al nuevo directivo, éste estará en condiciones de evolucionar hacia un estilo más democrático, incrementando la participación en la toma de decisiones, siempre que otras circunstancias ajenas (como, por ejemplo, la personalidad de sus nuevos superiores) no obstaculicen dicho proceso.

\section{EL LIDERAZGO SITUACIONAL}

Más elaborada que la anterior, y uno de los modelos de mayor uso en los programas de formación de directivos, es la teoría del liderazgo situacional construida por HERSEY y BLANCHARD (13) tras sus investigaciones sobre el comportamiento de los grupos. La variable situacional escogida por ambos como eje de su modelo es la madurez de los subordinados. Previamente HERSEY y BlANCHARD definen ésta como «la presteza para abordar la tarea encomendada al grupo».

De acuerdo con el comportamiento de esta variable, medida individualmente o en el grupo en su conjunto, el directivo tiene la posibilidad de ir adaptando su comportamiento a la situación existente. Un nivel bajo de madurez exigirá o conllevará una tutela muy fuerte, y conforme el grado de madurez sea mayor aquélla podrá reducirse y aparecerá la delegación.

Se ha comparado la relación entre el directivo-líder y sus seguidores con la relación padre e hijo, en el marco del «ciclo vital», que es como Hersey y BlanCHARD denominan su modelo. Del mismo modo que los padres van reduciendo su control conforme los hijos se van haciendo mayores, los directivos tienen que compartir la toma de decisiones con sus colaboradores en la medida en que éstos tienen más experiencia en su trabajo, ya que de otro modo las expectativas de unos y otros se verían frustradas, abriéndose paso a los conflictos interpersonales, la insatisfacción, un menor rendimiento, etcétera.

(13) Hersey, Paul, y BLANCHard, Ken; «So you Want to Know Your Leadership Style?», Training and Development Journal, febrero 1974; Management of Organizational Bebavior: Utilizing Human Resources, Prentice-Hall, Nueva Jersey, 1982.

HERSEY, Paul: Le leader situationnel, Les Editions d'Organisation, París, 1989.

En español, RoBBins, S.: op. cit., pp. 255-257, y PEÑa BAZTÁN, M.: La psicología y la empresa, Ed. Hispano Europea, Barcelona, 1985, pp. 282-285, entro otros. 


\section{La madurez de los subordinados}

Ya hemos dicho que el liderazgo situacional gira sobre la madurez de los subordinados. Esta madurez tiene dos componentes: la madurez para el trabajo, que se refiere a los conocimientos y destrezas que permiten actuar profesionalmente sin tener que recurrir a la dirección de otros y la madurez sicológica, concerniente al grado de automotivación o de dependencia exterior para animarse a efectuar determinadas tareas.

Como se ve más claramente en el siguiente gráfico (14), esta madurez se define en cuatro etapas. En $M 1$ resulta muy baja, sin que existan posibilidades técnicas ni sicológicas para desarrollar el trabajo por sí solo; $M 2$ reflejaría la situación en la que el colaborador tiene motivación para actuar pero no está en sesión de los conocimientos precisos; en $M 3$ se está en un alto nivel de madurez, en posesión tanto de los conocimientos como de la motivación para llevar a cabo el trabajo de que se trate.

Madurez del subordinado

\begin{tabular}{|c|c|c|c|}
\hline \multirow{2}{*}{$\frac{\text { Alta }}{M 4}$} & \multicolumn{2}{|c|}{ Moderada } & \multirow{2}{*}{$\frac{\text { Baja }}{M 1}$} \\
\hline & M3 & M2 & \\
\hline Competente & Competente & Incompetente & Incompetente \\
\hline $\begin{array}{c}\text { y } \\
\text { motivado }\end{array}$ & $\begin{array}{l}\text { pero } \\
\text { resistente }\end{array}$ & $\begin{array}{c}\text { pero } \\
\text { motivado }\end{array}$ & $\begin{array}{c}y \\
\text { resistente }\end{array}$ \\
\hline $\begin{array}{c}o \\
\text { confiado }\end{array}$ & 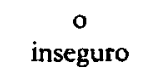 & $\begin{array}{c}o \\
\text { confiado }\end{array}$ & $\begin{array}{c}\circ \\
\text { inseguro }\end{array}$ \\
\hline
\end{tabular}

MADUREZ

INMADUREZ

\section{El comportamiento del directivo}

A estos componentes del concepto de madurez de los subordinados se incorporan dos elementos de medida ya clásicos en el análisis del liderazgo: el comportamiento centrado en la tarea (productividad), que se produce cuando el directivo comunica unidireccionalmente cuáles son las características del trabajo a desarrollar y la forma de llevarlo a cabo, y el comportamiento centrado en las personas (relaciones interpersonales), caracterizado por una comunicación bidireccional en que el líder actúa dando apoyo socioemocional. A su vez, ambas se clasifican en altas o bajas.

(14) HERSEY, Paul: op. cit., p. 56. 
Más en detalle, en el caso del eje correspondiente al comportamiento centrado en la tarea, se trata de identificar en qué medida el responsable definirá los roles a desempeñar e indicará quién, qué, cómo, dónde y cuándo se lleva a cabo aquélla; todo ello referido al establecimiento de objetivos, organización, plazos, dirección y control. En lo que concierne al comportamiento centrado en la relación, se trata, a su vez, de ver en qué medida el directivo dialogará, comunicará, escuchará, proporcionará apoyo sicoemocional y facilitará la interacción.

$\mathrm{El}$ gráfico que refleja el conjunto del modelo nos permite ver con más claridad cómo opera la relación entre la madurez de los subordinados y el estilo de liderazgo que se considera más apropiado. Este se representa mediante una curva en forma de campana que recorre los cuadrantes correspondientes a los diferentes estilos posibles.

(Alto)

\section{ESTILO DEL LIDER}

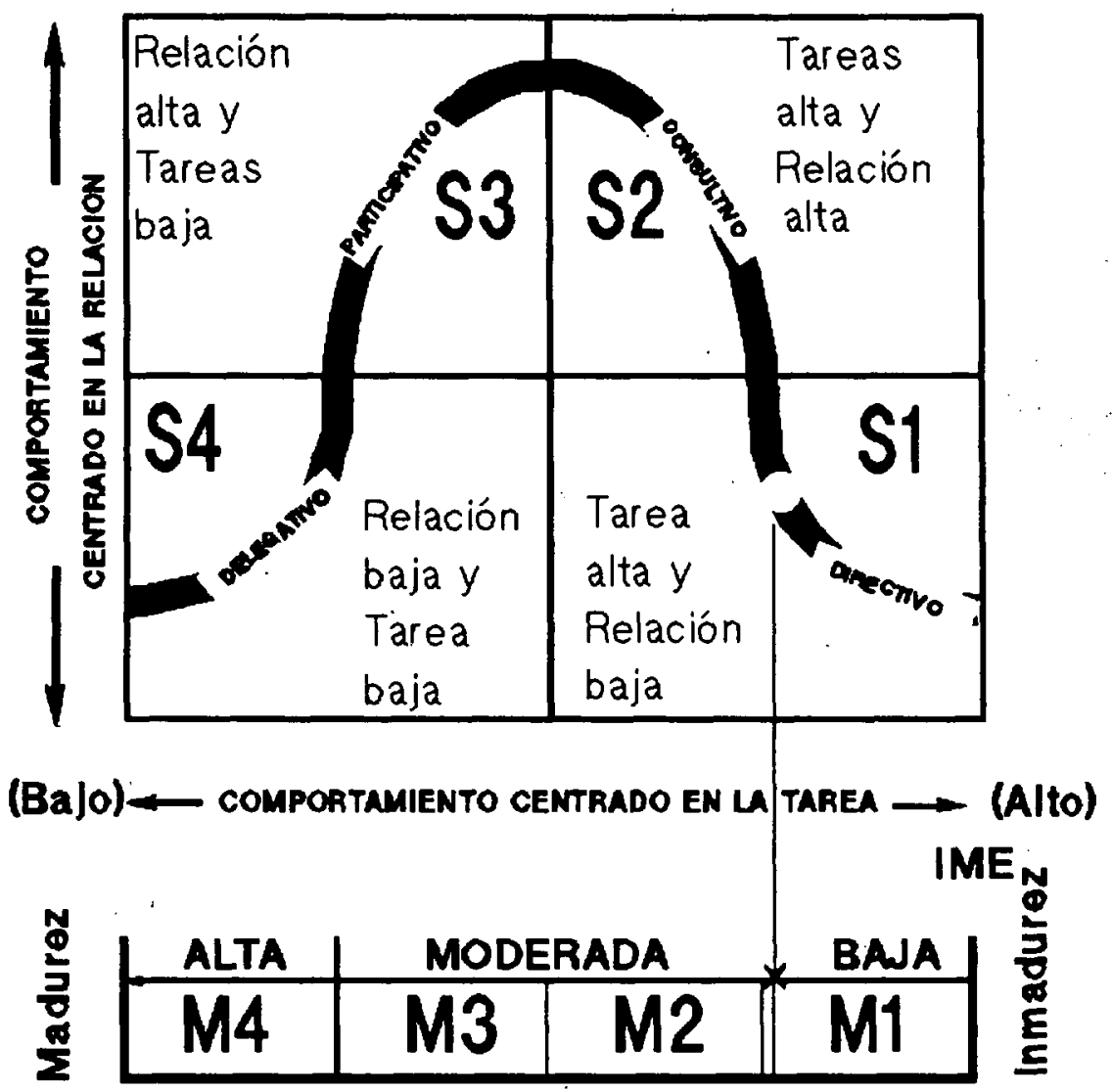

MADUREZ DE LOS SUBORDINADOS 
A medida que evoluciona el grado de madurez del colaborador concreto o del equipo en su conjunto, el estilo de liderazgo apropiado se desplaza a lo largo de la curva. Hay que tener en cuenta que el sentido de la evolución no es unidireccional desde la inmadurez a la madurez, sino que pueden producirse regresiones ocasionadas por la complejidad de los nuevos proyectos a realizar, por un cambio en el clima organizacional o por la incidencia de conflictos personales ajenos al trabajo.

\section{Aplicación del modelo}

¿Cuál es la forma de aplicar el modelo? En primer lugar es preciso identificar el grado de madurez de los colaboradores, ya que nadie es maduro o inmaduro en términos absolutos. Por otra parte, es preciso que el directivo sea casuístico y efectúe la valoración en función de la tarea o proyecto que tenga que llevar a cabo a través de sus colaboradores. Por ejemplo, entre nosotros un Jefe de Servicio y sus propios subordinados pueden tener un grado de madurez $M 4$ para aplicar una normativa determinada, pero estar en $M 1$ o $M 2$ si se trata de llevar a cabo un estudio estadístico sobre su aplicación que les permita sacar conclusiones para luego proponer la reforma de la misma, redactar un borrador de norma, etcétera.

El grado de madurez así identificado se señala en la escala correspondiente (zona inferior del gráfico) y se traza una línea vertical hasta alcanzar la curva de los estilos posibles de liderazgo que puede ejercer el directivo (para facilitar la comprensión del funcionamiento del modelo, esta línea vertical, que no está representada en los gráficos originales de HERSEY y BLANCHARD, nosotros la hemos incluido denominándola IME: Identificación de Madurez y Estilo). El punto de intersección corresponde al estilo de liderazgo que se considera más apropiado al momento y a la tarea que es preciso llevar a cabo.

Según el modelo, los estilos posibles de liderazgo son cuatro: S1, o Directivo, consistente en una alta orientación a la tarea y baja bacia la relación; $S 2$, o Consultivo, con un comportamiento de alta orientación tanto bacia la tarea como bacia las relaciones; S3, o Participativo, de alta relación y baja tarea, y $S 4$, o Delegatorio, en el que hay un comportamiento de relación baja y tarea baja. La esencia del modelo consiste en combinar estos cuatro estilos de liderazgo (S1-S4) con los cuatro niveles en que se mide la madurez de los subordinados (M1-M4) que ya hemos visto anteriormente.

En el caso del estilo Directivo, el comportamiento se basará en dar las instrucciones precisas y controlar muy de cerca los resultados. En el estilo Consultivo, el dirigente explicará sus decisiones y fomentará 
que le hagan preguntas sobre ellas. En el Participativo, compartirá sus ideas con los colaboradores y ayudará en la toma de decisiones. Finalmente, en el estilo Delegatorio, delegará sus responsabilidades tanto en lo que se refiere a las decisiones como a su ejecución.

Volvamos al supuesto del Jefe de Servicio y al encargo de que lleve a cabo un estudio que le permita elaborar un borrador de norma que sustituya a la que se está aplicando. Una vez determinado que su grado de madurez para esta tarea es M1, se deduce que el estilo inicial de liderazgo más eficaz para regir el comportamiento de su Subdirector general o incluso del Director, si la materia tiene la suficiente importancia, será el estilo S1, fuertemente orientado hacia la tarea y de baja relación.

Esto no quiere decir que imperen la dureza o la frialdad en las relaciones, sino que el tiempo que el directivo dedique a despachar sobre el proyecto debe ser utilizado sobre todo en indicar y supervisar el quién, qué, cómo, cuándo y dónde se lleva a cabo el trabajo. Sólo cuando el proyecto comience a dar muestras de estar bien diseñado y el colaborador (y su equipo) comience a demostrar capacidad e iniciativa en relación con su ejecución será conveniente modificar el estilo de liderazgo para reforzar su motivación mediante un apoyo socioemocional propio del estilo M2.

Con el mismo Jefe de Servicio, el directivo deberá ser suficientemente flexible como para mantener simultáneamente un estilo de trabajo delegatorio cuando se trate de seguir aplicando en su puesto de trabajo la normativa vigente, puesto que es una tarea que él y su equipo dominan sobradamente y para la que tienen la suficiente motivación, según se venía demostrando.

Correspondencia entre el estilo y la madurez (15)

\begin{tabular}{|c|c|c|c|c|}
\hline & Madurez & & Estilo & Descripción \\
\hline $\mathrm{Ml}$ & $\begin{array}{l}\text { Incompetente y } \\
\text { resistente o inseguro }\end{array}$ & S1 & $\begin{array}{l}\text { Fuertemente directivo } \\
\text { Débilmente relacionado }\end{array}$ & $\begin{array}{l}\mathrm{Da} \text { las instrucciones precisas } \\
\text { y sigue después los resultados }\end{array}$ \\
\hline M2 & $\begin{array}{l}\text { Incompetente pero } \\
\text { motivado o confiado }\end{array}$ & S2 & $\begin{array}{l}\text { Fuertemente directivo } \\
\text { Fuertemente relacionado }\end{array}$ & $\begin{array}{l}\text { Explica sus decisiones y } \\
\text { fomenta las preguntas }\end{array}$ \\
\hline M3 & $\begin{array}{l}\text { Competente pero } \\
\text { resistente o inseguro }\end{array}$ & S3 & $\begin{array}{l}\text { Débilmente directivo } \\
\text { Fuertemente relacionado }\end{array}$ & $\begin{array}{l}\text { Comparte las ideas y } \\
\text { facilita la delegación } \\
\text { de decisiones }\end{array}$ \\
\hline M4 & $\begin{array}{l}\text { Competente y } \\
\text { motivado o confiado }\end{array}$ & S4 & $\begin{array}{l}\text { Débilmente directivo } \\
\text { Débilmente relacionado }\end{array}$ & $\begin{array}{l}\text { Delega sus responsabilidades } \\
\text { para las decisiones } \\
\text { y la ejecución }\end{array}$ \\
\hline
\end{tabular}

(15) HeRSEY, Paul: op. cit., p. 59. 
En resumen, los cuatro estilos de liderazgo de la teoría situacional se orientan al logro de una mayor eficacia en el ejercicio de la función directiva, mediante la aplicación del estilo más adecuado a cada persona y a cada tarea en un momento dado. Como se ha visto, el modelo también permite que de forma natural el directivo, actuando gradualmente y siempre sin mecanicismos, vaya adaptando su comportamiento a las necesidades técnicas y socioemocionales de sus colaboradores, tanto individual como grupalmente.

\section{COMUNICACION}

La comunicación en el seno del grupo social se ha definido como «la relación, de innumerables aspectos, formas y variedades, que une fundamentalmente a cada hombre al mundo de los hombres y a los hombres entre sí» (16). Ya hace años George MEAD habia insistido en la importancia de este elemento de relación, por lo que implicaba la participación con otros: «Esto exige que el Otro aparezca en el Yo, que el Yo se identifique en el Otro y que se haga consciente de sí mismo gracias a otro» (17).

Más modernamente, y sobre todo en el mundo del management, se considera comunicación a la emisión de mensajes que pretenden provocar determinados comportamientos en aquellas personas a las que van destinados. Incluso, refiriéndose al mundo de la empresa, se habla de la aparición de una ciencia de las comunicaciones, ya que «en la sociedad moderna no hay prácticamente acción que no encuentre su correspondencia en una comunicación cualquiera... Se podría decir que al lado del mundo de las acciones y de los objetos existe un verdadero mundo de la comunicación en correlación estrecha y necesaria con el precedente» (18).

Son cuatro (19), básicamente, los tipos de información necesarios en un equipo de trabajo para contribuir a alcanzar los requisitos constitutivos y de funcionamiento eficaz que hemos enumerado en la Introducción de este trabajo, que deben ser comunicados adecuadamente:

1. Información operativa. Es aquella necesaria técnicamente para la ejecución del trabajo: características, plazos, dónde, cómo, etc. En gran medida es una información vinculada a la definición del puesto

(16) Hesnard, A.: Psychnalyse du lien interhumain, PUF, París, 1957.

(17) MEAD, George: L'esprit, le Soi y la Societé, PUF, París, 1963, p. 215.

(18) Moles, A., y Duguet, M.: Les comunications en l'entreprise, Entreprise Moderne d'Edition, París, 1966.

(19) MuCCHIELl, Roger: Communication et reseaux de communications (8." edición), Editions ESF, Paris, 1991, p. 72. 
de trabajo, pero su ausencia, paradójicamente muy frecuente, constituye uno de los motivos de insatisfacción importantes.

2. Información motivadora. Se trata de informaciones que permiten a los miembros del equipo situarse en el contexto y tener un conocimiento suficiente de los objetivos, medios, normas, dificultades y preocupaciones del equipo en su conjunto.

No es necesario, y tampoco conveniente en la mayoría de las ocasiones, que todos los miembros del equipo estén en posesión de toda la información de que disponen los máximos responsables. Su posesión no necesariamente contribuye a incrementar la motivación; sin embargo la ausencia de la información imprescindible para cada nivel de colaboración resulta de vital importancia para mantener aquélla.

Es este un tipo de información especialmente importante cuando se quiere llevar a cabo un proceso de cambio y debe proporcionarse en las fases preparatorias del mismo.

3. Información promocional. Como su propio nombre indica se refiere a las posibilidades de realización y progresión profesional de los miembros del equipo, bien sea dentro del mismo o fuera, como consecuencia de su trabajo presente en él.

4. Información general. Concierne a aquellas cuestiones ajenas al propio equipo pero que pueden resultar de interés para sus miembros y que contribuyen a su socialización en el seno de la organización en la que se integra el equipo: derechos, obligaciones, ayudas sociales, etcétera.

Sin embargo no es fácil lograr unos buenos niveles de comunicación en la transmisión de esta información, hasta el punto de que para tratar el tema a menudo se utiliza la expresión, ya clásica, «el problema de la comunicación». A la ambigüedad o el hermetismo del mensaje hay que unir en ocasiones los malentendidos originados por la subjetividad del receptor o simplemente porque éste y el emisor no hablen el mismo lenguaje. Así, como ilustración podemos exponer dos ejemplos (20): FREUD:

El primero, ejemplo de malentendido, proviene de la obra de

Un médico deja la cabecera de una enferma y moviendo la cabeza de un lado para otro le dice al marido que le acompaña: «Pues no me gusta nada.» «A mí hace mucho tiempo que dejó de gustarme», responde el marido asintiendo. 
El segundo, ilustrativo de la utilización de lenguajes diferentes, está extraído de la vida militar:

Un capitán preocupado por la cultura general de la tropa, deseando aprovechar la inminencia de un eclipse solar para impartir una lección de cosmografía, decide reunir a los hombres de su compañía en el patio, si hace bueno, en el momento del eclipse, y, previendo que pueda llover, se propone, en ese caso, explicar el fenómeno en el cobertizo. El mensaje pasa del capitán al teniente, del teniente al brigada, del brigada al sargento y del sargento al cabo, que avisa a los soldados del siguiente modo: «Mañana, un eclipse tendrá lugar en el patio por orden del capitán. Si llueve, el capitán hará el eclipse en el cobertizo.»

Más sistemáticamente, ¿cuáles son las causas del fracaso en la comunicación?

En todo proceso de comunicación hay necesariamente un emisor, un receptor, un canal de comunicación y un mensaje en los que se pueden producir deficiencias, distorsionándose el resultado final. En esta ocasión nosotros nos limitaremos a los potenciales factores de fracaso correspondientes a los dos primeros elementos, el emisor y el receptor, ya que son los integrantes del equipo de trabajo que nos ocupa.

\section{Variables en relación con el emisor (21)}

En primer lugar está el cuadro de referencia del emisor, es decir, el sistema de opiniones, de ideas, del saber, así como el sistema de normas y de valores en relación con los cuales se organiza y adquiere sentido aquello que se va a decir. Es un cuadro de referencia que está implícito para el emisor y que le sirve de soporte para aquello que expresa.

A este cuadro de referencia es preciso unir, en estrecha relación, las connotaciones de los términos empleados por el emisor en su mensaje en función de dicho cuadro. Es decir, todo aquello que cualquier término pueda sugerir, evocar o implicar, de forma más o menos clara, para aquel que lo utiliza.

En segundo plano tenemos las actitudes del emisor en relación con el destinatario del mensaje. Dentro de este aspecto podemos hacer una doble distinción que nos ayude a comprenderlo mejor:

(21) Cfr. MuCCHIELLI: op. cit., pp. 10 y ss., cuyo esquema se sigue. 
- Las actitudes bacia el Otro en general o, dicho de otra manera, la actitud social global del emisor y su concepción de las relaciones humanas.

- Las actitudes bacia el destinatario en tanto que individuo, que se hallan condicionadas por los sentimientos de simpatía o antipatía, los prejuicios y los estereotipos, así como la idea que el emisor imagina que el destinatario se ha formado sobre él.

En tercer lugar figura la influencia del contexto en el que tiene lugar la comunicación, ya que la existencia de determinado público o determinadas condiciones sociales transforma no sólo la presentación del mensaje, sino el propio contenido.

Finalmente señalaremos la idea que se tiene del objetivo de la comunicación, ya que según sean las motivaciones conscientes e inconscientes se utilizará un lenguaje determinado, un canal u otro, etcétera.

Variables en relación con el receptor

Más allá de la simple repetición de lo que ya se ha expuesto en relación con el emisor, en este caso se puede efectuar la siguiente clasificación:

El estado de preparación del receptor, es decir, el conjunto de disposiciones existentes a priori en el receptor, así como las desencadenadas automáticamente ante la perspectiva de recibir un mensaje proveniente de un emisor determinado. Este conjunto puede desagregarse del siguiente modo:

- Influencia de las informaciones previas, fundadas en la propia experiencia del receptor.

- Influencia de la personalidad del emisor, es decir, el conocimiento que se tenga sobre él o la credibilidad que posea. La actitud de un receptor será distinta si se dirije a él una persona cuyas opiniones no comparte o que carece de credibilidad por su comportamiento anterior, a la que tendrá si su interlocutor es un afín.

- Influencia del destino que se pretende dar a la información recibida. En este sentido la comunicación será tanto más eficaz en la medida que coincidan los objetivos de emisor y receptor.

- La decodificafión del mensaje, o su comprensión en virtud del conocimiento que se tenga del «código».

Finalmente, la reacción ante el emisor y la propia emisión, ya que, por ejemplo, en las comunicaciones cara a cara el emisor hábil puede ajustar su comportamiento y su mensaje en función de las reacciones 
que éste vaya produciendo en el receptor, mejorando de este modo la comunicación. Constituye esto un adelanto de la retroalimentación, que tanta importancia tiene en la dinámica de la comunicación.

Dentro de esta última variable es necesario hacer una referencia a la importancia de la comunicación no verbal, a lo que se denomina para-lenguajes (apariencia, gestos, mímica, miradas, sonidos...), que completa el mensaje verbal, confirmándolo, matizándolo o contradiciéndolo (22).

Para hacer frente al «problema de la comunicación» se han desarrollado en las últimas décadas numerosas técnicas que la hacen más fácil y eficaz al posibilitar el hacer frente a los riesgos contenidos en los factores que acabamos de ver. Asumiendo que la comunicación en el seno de un equipo de trabajo es un proceso social caracterizado por la interacción, en el que existe una distribución y una representación de roles, vamos a exponer a continuación dos técnicas dirigidas a facilitar dicho proceso de comunicación entre los miembros del equipo: los estilos cognitivo-profesionales y el Análisis Transaccional.

\section{ESTILOS COGNITIVO-PROFESIONALES}

Nuestro mensaje, nuestra palabra, para ser conniventes requieren, como ya hemos señalado en la introducción a este capítulo, que nos reconozcamos en nuestros interlocutores $o$, dicho de otro modo, que comprendamos cuáles son sus preocupaciones dominantes para adaptarnos a ellas. Con ello estaremos en condiciones de expresar nuestras ideas de tal forma que sean mejor comprendidas y acogidas por sus destinatarios. Sin embargo, este esfuerzo de adaptación debe tener límites, ya que la actuación en un estilo contrario al propio puede colocar a la persona en condiciones de inferioridad, como consecuencia de la posición forzada que se adopta en la interacción.

Siguiendo a DraKe, se han definido cuatro extremos posibles en función de las preocupaciones cognitivo-profesionales de las personas (23). A su vez, esos cuatro polos configurarían cuatro estilos de comportamiento.

- El polo del ¿qué?, correspondiente a las personas orientadas hacia la acción.

- El polo del ¿cómo?, que incluiría a las personas orientadas hacia los métodos.

(22) DAvIS, Flora: La comunicación no verbal (6." edición), Alianza Editorial, Madrid, 1982.

(23) CASSE, P.: Training for the Cross-Cultural Mind (pp. 125-133, SIETAR, Washington, abril, 1980, a partir de DRAKE, BEAM AND ASSOCIATES, «The four styles, how to recognize them and how to adjunst them», Nueva York). 
- El polo del ¿quién?, característico de aquellos orientados hacia el hombre, hacia las otras personas.

- El polo del ¿por qué?, propio de aquellos orientados hacia las ideas.

LOCALIZACION DE LAS PREOCUPACIONES DOMINANTES (24)

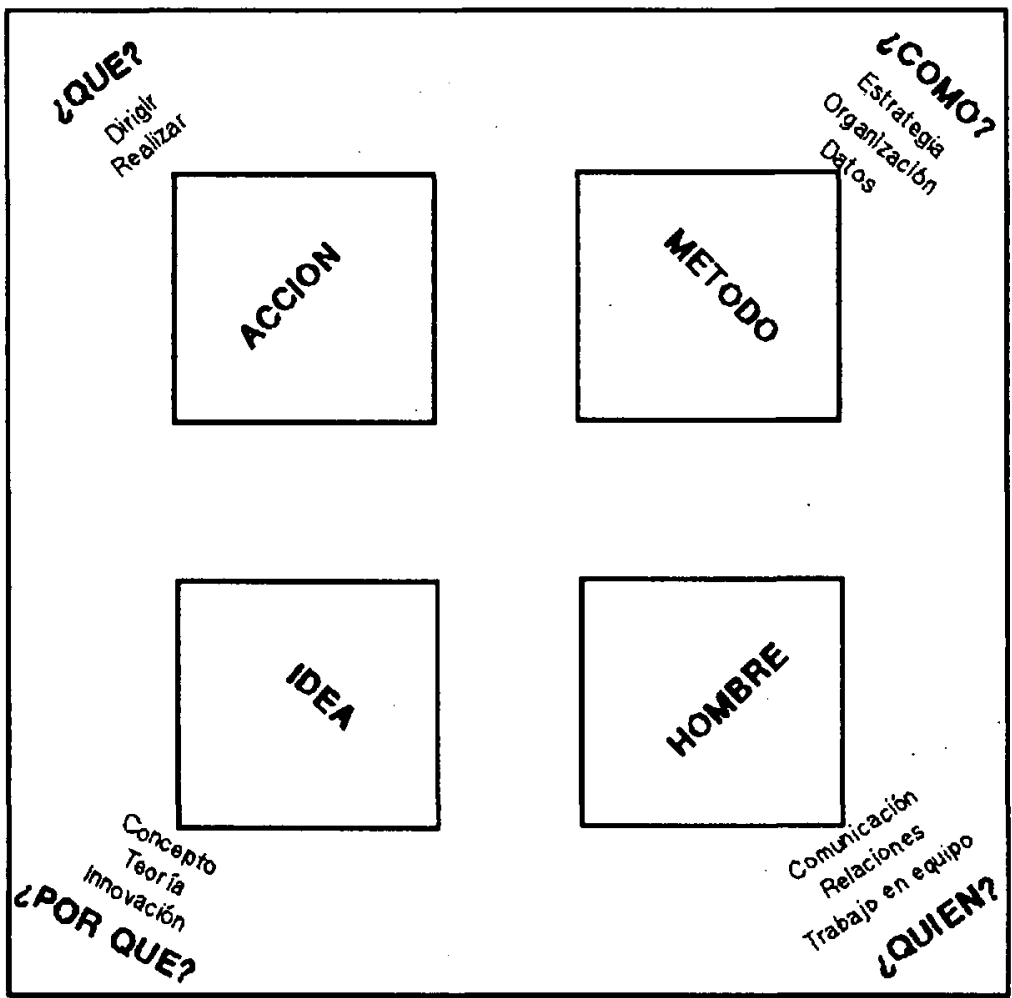

A cada una de estas actitudes posibles extremas se le ha dado una denominación que refleje, en la medida de lo posible, las tendencias del comportamiento. Así, los preocupados por el ¿qué?, y orientados hacia la acción, han recibido la denominación convencional de Dinámicos. Aquellos cuyas preocupaciones se centran en el ¿cómo?, en los que predomina la orientación hacia los métodos, se denominan Reflexivos. A su vez, los protagonistas del ¿por qué?, orientados hacia las ideas, son identificados como Intuitivos. Y por último, a aquellos preocupados por el ¿quién?, en quienes las personas constituyen la punta de flecha de su orientación, son denominados Perceptivos.

(24) Bellenger, Lionel: L'expression orale, Editions ESF, París, 1989, p. 89. 
¿Cómo reconocer a nuestros interlocutores, cómo identificar, de acuerdo con estos estilos, a los miembros de nuestro equipo de trabajo, para poder adaptarnos a su comportamiento y resultar más influyentes?

Llegados a este punto es preciso aclarar que el establecimiento de los cuatro estilos se ha llevado a cabo en el buen entendimiento de que no hay estilos puros en sentido estricto, sino inclinaciones dominantes hacia una u otra orientación, pero siempre con influencias más o menos presentes de los otros estilos.

Las experiencias empíricas en las que se fundamenta la formulación de los cuatro estilos, y las aplicaciones posteriormente realizadas, muestran que se puede reconocer o clasificar a las personas escuchando atentamente de qué bablan y analizando cómo se nos aparecen profesionalmente.

Veamos ahora el desarrollo de las características básicas de cada uno de los estilos, cómo tienden a manifestarse en su trabajo y cómo son percibidos por los demás.

\section{Dinámicos}

Como hemos visto, están fuertemente orientados hacia la acción y, por tanto, concederán una gran importancia a los resultados que dicha acción produce. Se mostrarán preocupados por los objetivos que deben alcanzar y, en consecuencia, las expresiones «responsabilidad», «productividad» y «eficacia» aparecerán en su discurso con cierta frecuencia. Por esta razón aquellos proyectos cuyos resultados no vean con claridad o no les resulten atractivos, serán para ellos escasamente motivadores y procurarán no llevarlos a cabo.

Aunque preocupados fundamentalmente por el presente (para los dinámicos el pasado es apenas un punto de referencia y el futuro no existe, ya que se construye día a día), asumirán con agrado el protagonismo de procesos de cambio que contribuyan a la mejora de la situación actual; de ahí que las referencias «al progreso» o a los «retos» sean habituales en ellos, en la medida en que éstos puedan medirse.

En su actuación profesional las alusiones a los estudios y a la planificación serán escasas, puesto que fundamentan su acción más en la propia experiencia que sobre conceptos teóricos, si bien, en ocasiones, pueden hacer referencia al mundo de las ideas y los conceptos, una vez que se hayan convencido de la posibilidad de llevarlos a la práctica.

Los dinámicos son percibidos por los demás como personas pragmáticas, directas, decididas y enérgicas, que toman las decisiones con rapidez. Por este motivo se recurre a ellos cuando se trata de llevar a cabo proyectos urgentes $\mathfrak{u}$ otros en los que los resultados son especialmente importantes. 
Cuando la marcha de los acontecimientos no les sea favorable, y los dinámicos entren en lo que se conoce como «aplicación ineficaz», tenderán a ser autoritarios, teniendo problemas de relación en su afán por imponer sus criterios para pasar a la acción. En estas circunstancias despreciarán la fase de planificación, insistiendo en que lo importante en comenzar a ejecutar los primeros pasos, si es preciso recurriendo a la improvisación, ya que la mera acción les sirve como terapia que alivia su ansiedad.

Sometidos a tensión, los dinámicos llegarán, si las circunstancias les obligan a ello, a atropellar los sentimientos de los demás para imponerse, actuando sesgadamente y valorando a los miembros del equipo en función de su adhesión.

\section{Reflexivos}

Se podría decir que constituyen el polo opuesto a los dinámicos que acabamos de ver. Para ellos sólo es posible pasar a la acción una vez que los problemas han sido analizados cuidadosamente, en sus diferentes facetas, y se han sopesado las diversas alternativas existentes hasta encontrar la más adecuada para dar solución.

Orientados hacia el método, se referirán frecuentemente a los «datos», el «análisis» de los mismos, el «procedimiento» y la «organización». Basarán su trabajo en las conclusiones extraídas de sus análisis y en la lógica, prescindiendo de la especulación y de los sentimientos propios o ajenos. Las innovaciones les parecerán sumamente peligrosas hasta que todas sus posibilidades e implicaciones hayan sido estudiadas cuidadosamente.

En cuanto a la toma de decisiones se mostrarán muy cautos con las ajenas hasta haberlas contrastado con su propia información sobre el asunto. Si se trata de decisiones que ellos deben adoptar sólo lo harán cuando estén convencidos de que no les queda ningún aspecto del problema por analizar y los riesgos de que aparezca algún elemento nuevo hayan desaparecido. En esta línea nos encontraremos frecuentemente en sus intervenciones profesionales con términos como «prudencia», «reflexión» y «precipitación», esta última en sentido negativo, claro está.

Pasado, presente y futuro tienen para ellos el mismo valor, bien sea como fuente de información o como instancia de proyección de determinadas realizaciones.

En su entorno los reflexivos aparecerán como profesionales sistemáticos, lógicos, neutrales en caso de conflicto y fiables, en los que se podrá confiar cuando se trate de tareas complejas que requieran una cuidadosa planificación o el análisis de problemas potenciales. 
En «aplicación ineficaz», como consecuencia de encontrarse sometidos a presión o porque los acontecimientos no se desarrollen de acuerdo con sus expectativas, pueden constituir una rémora por su insistencia en reflexionar en detrimento de la acción, haciendo gala de una paciencia analítica que en opinión de otros puede resultar paralizante por su indecisión.

Identificación de los estilos (25)

\begin{tabular}{|c|c|c|c|}
\hline \multicolumn{2}{|c|}{ Dinámicos } & \multicolumn{2}{|c|}{ Reflexivos } \\
\hline \multicolumn{2}{|c|}{$\begin{array}{l}\text { Preocupación: ¿quê? } \\
\text { Orientación: bacia la acción }\end{array}$} & \multicolumn{2}{|c|}{$\begin{array}{l}\text { Preocupación: ‘cómo? } \\
\text { Orientación: bacia el método }\end{array}$} \\
\hline \multicolumn{2}{|l|}{ Hablan de: } & \multicolumn{2}{|l|}{ Hablan de: } \\
\hline - Resultados & - Experiencia & - Datos & - Hechos \\
\hline - Objetivos & - Retos & - Procedimientos & - Análisis \\
\hline - Productividad & - Realización & - Planificación & - Observación \\
\hline - Adecuación & - Cambio & - Organización & - Comprobación \\
\hline - Eficacia & - Decisiones & - Control & - Detalles \\
\hline - Progreso & - Presente & - Pruebas & \\
\hline - Responsabilidad & & & \\
\hline
\end{tabular}

Se nos aparecen como:

- Pragmáticos

- Directos

Se nos aparecen como:

- Impacientes

- Sistemáticos

- Prudentes

- Rápidos

- Decididos

- Lógicos

- Concretos

- Poco emotivos

- Enérgicos

- Neutrales

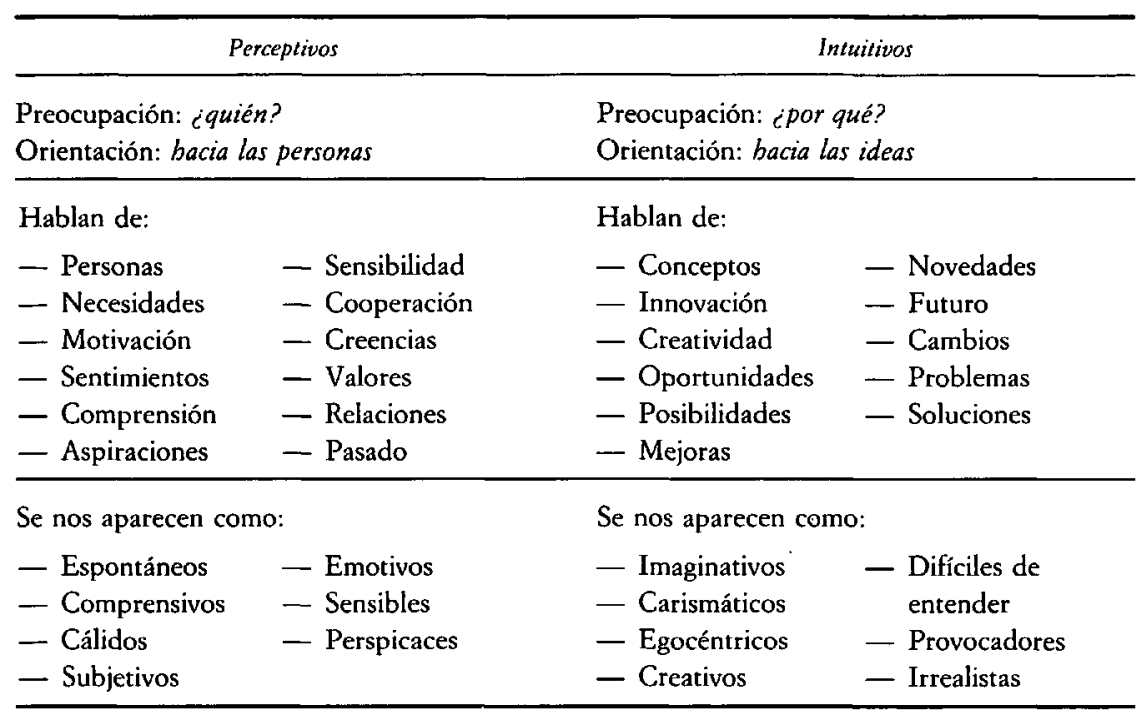

(25) Bellenger, Lionel: op. cit., p. 90. 


\section{Perceptivos}

Como consecuencia de su orientación hacia las personas, a los perceptivos les agrada llevar a cabo proyectos que impliquen el establecimiento de relaciones sociales y el desarrollo de contactos interpersonales. En este contexto se desenvuelven bien por su capacidad para ponerse en el lugar de los demás y comprender con sensibilidad sus problemas y preocupaciones.

En cuanto a las dimensiones temporales dan una notable importancia al pasado, resultando la experiencia una fuente de información que valoran altamente. Por el mismo motivo determinados valores tradicionales son apreciados por ellos.

Les escucharemos a menudo referirse al «equipo», los «deseos», las «necesidades» y los «sentimientos». Estas preocupaciones les permiten detectar problemas interprofesionales subyacentes en los equipos y prever las reacciones que se pueden desencadenar a partir de determinadas actuaciones. En estos casos se muestran hábiles para imaginar y desarrollar las acciones contingentes adecuadas para reforzar la cooperación y el espíritu de equipo y vencer resistencias.

Para las personas que les rodeen, los perceptivos aparecerán como comprensivos, cálidos en el trato, sensibles y perspicaces; cualidades éstas que les harán ser muy valorados en aquellos proyectos en los que sea preciso tener un tacto especial para no herir susceptibilidades y garantizarse la colaboración de los implicados.

Por el contrario, los perceptivos en aplicación «ineficaz» podrán tornarse subjetivos y muy susceptibles ante las críticas, ocasiones en las que, si lo consideran preciso, recurrirán al chantaje emocional con superiores y colaboradores para salvar determinadas situaciones. Sometidos a presión tenderán a abandonar la reflexión para actuar basándose en intuiciones sin ninguna base empírica.

\section{Intuitivos}

Orientados hacia las ideas, los intuitivos acostumbran a poner en cuestión lo establecido, lo que se viene haciendo. Volcados hacia el mundo de las posibilidades, se desarrollan plenamente imaginando modelos inéditos que aporten soluciones a problemas complejos.

Al tratar con ellos hablarán de «futuro», «concepto», «innovación», «problemas» y «mejoras», sintiéndose estimulados sobre todo por el esfuerzo creador de soluciones, más que por su aplicación concreta a la realidad.

Dotados de una notable capacidad teórica, disfrutarán estableciendo relaciones entre diversos elementos con el mayor nivel de abstrac- 
ción posible. En esta tarea actuarán introspectivamente tratando de dar significado práctico al producto de su imaginación y desarrollando nuevos métodos e instrumentos.

Profesionalmente el futuro es la dimensión temporal con la que se encuentran más identificados. Para ellos lo importante no es lo que se hacía en el pasado o lo que se hace actualmente, sino lo que tendría que hacerse en el futuro.

De acuerdo con todo lo anterior, a los ojos de los demás tendrán una imagen de gentes difíciles pero imaginativas, llenas de ideas y en ocasiones se presentarán como visionarios o carismáticos. Resultan muy útiles cuando es preciso desarrollar trabajos con cierta profundidad

SINTESIS DE LAS CARACTERISTICAS DE LOS ESTILOS

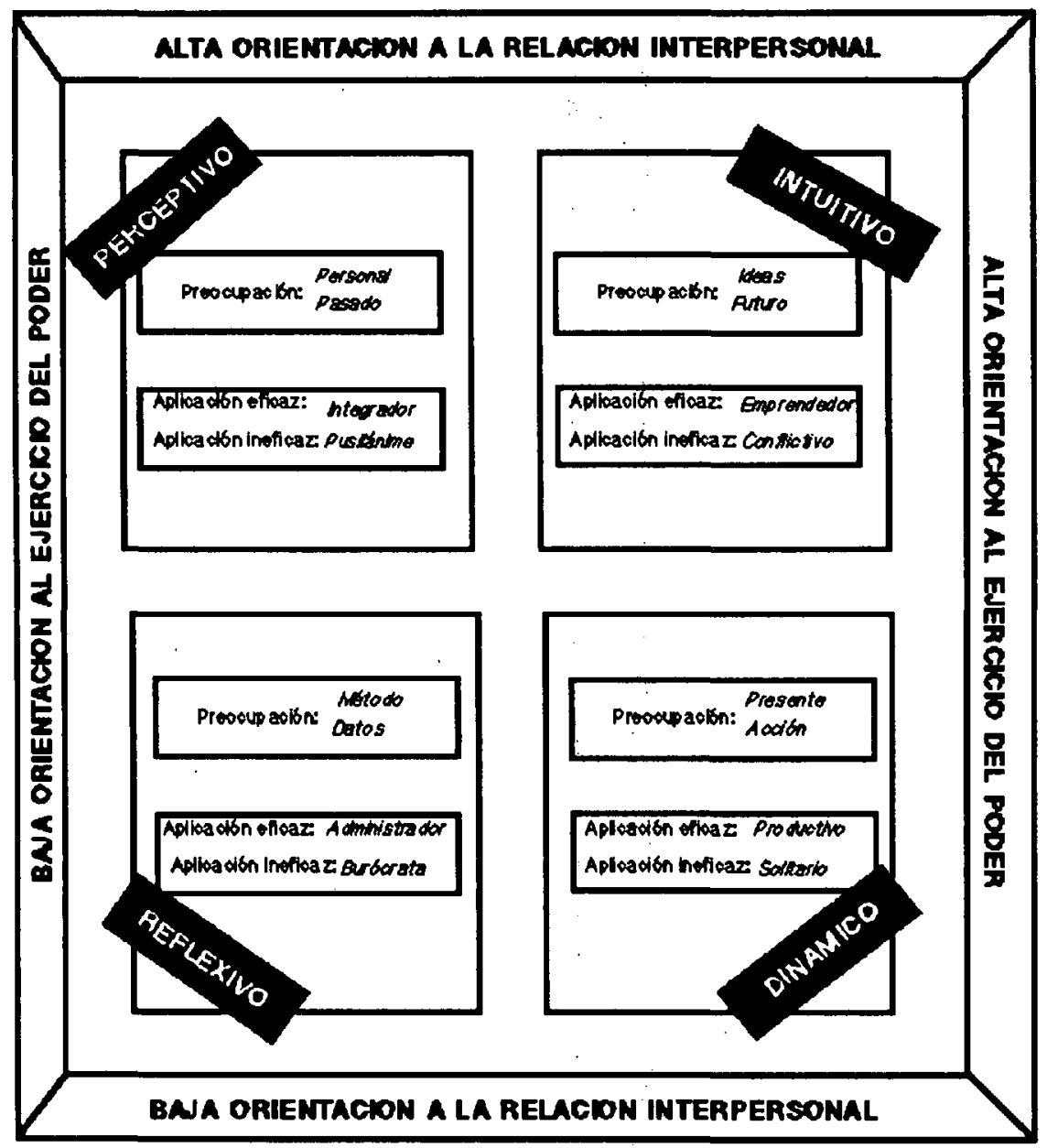


teórica, elaborar políticas, identificar problemas o priorizar programas de actuación.

En los malos momentos o en estado de ansiedad, los intuitivos, en la imposibilidad de cultivar su egocentrismo, perderán el interés por los asuntos en los que consideren que no se aprecia la calidad de sus ideas y tenderán a despreciar a los demás por lo que consideran incapacidad para seguirles.

Es preciso insistir una vez más en que los cuatro estilos que hemos visto constituyen elaboraciones extremas de un modelo, que difícilmente pueden darse en la realidad en estado puro, lo mismo que en el caso de otras clasificaciones sicosociológicas. Lo normal es que exista un estilo dominante con influencias de los otros estilos.

De hecho, un profesional puede evolucionar, y así se ha comprobado, y la propia experiencia personal nos lo confirma, que determinados elementos del estilo cambian por la incidencia de diversos factores, especialmente por el condicionamiento que supone el desempeño de un puesto de trabajo de determinadas características. Así por ejemplo, entre nosotros los puestos de Subdirector general de Recursos, Jefe de Asesoría jurídica o Subdirector de Análisis económico obligarán a sus titulares a procesos de reflexión más intensos que los que se lleven a cabo como Subdirector general de Tránsito aéreo, Subdirector de Gestión económica o de Gestión de personal, más caracterizados por el impulso y la toma de decisiones. Y, lógicamente, cuando se produce un cambio de puesto es preciso efectuar un proceso de adaptación del estilo a las nuevas condiciones, sin que ello suponga un cambio de personalidad en las tendencias esenciales.

\section{La adaptación (26)}

En la aplicación del modelo de los estilos cognitivos, una vez conocido el estilo de nuestros interlocutores, y con anterioridad el nuestro propio, lo que procede es efectuar una aproximación al estilo de la persona con la que estamos interactuando. Con ello se pretende, exclusivamente, que el proceso de comunicación sea más eficaz, esto es, que nuestro mensaje sea mejor recibido y tenga más posibilidades de ser compartido y asumido.

Cuando se trate de comunicar con un Dinámico lo más apropiado será comenzar poniendo el acento en los resultados del proyecto o de la actuación que se está llevando a cabo o que se va a iniciar. Es decir, habrá que comenzar resaltando qué se pretende conseguir y, al mismo

(26) BELLENGER, Lionel: op. cit., pp. 91 y ss. 
tiempo, subrayar el aspecto práctico de la propuesta que se formula o de lo que ya se ha obtenido.

Los dinámicos se consideran siempre muy ocupados y, en cualquier caso, necesitan ir sin rodeos al núcleo de los asuntos. Por ello, sin entrar en explicaciones sobre cuáles son las diferentes alternativas existentes, sus ventajas o inconvenientes, hay que mostrarles cuál es la que se considera más apropiada para el supuesto que se esté tratando.

Finalmente se utilizarán, siempre que ello sea posible, ayudas visuales, gráficos, etc., que permitan captar con facilidad los elementos esenciales de un asunto sin tener que detenerse en aspectos secundarios.

En el caso de los Reflexivos la línea de adaptación consistirá en exponer los datos de que se disponga con objetividad y precisión, organizando la intervención de forma lógica y secuencial.

Llegado el momento de exponer las recomendaciones para futuras actuaciones convendrá enunciarlas todas con su correspondiente valoración, a fin de permitir al destinatario reflexivo que extraiga sus propias conclusiones de los datos que se le presentan.

En este sentido es muy importante no presionar a los reflexivos en una dirección determinada, por ejemplo poniendo especial énfasis en la idoneidad de una determinada alternativa; tal comportamiento probablemente generará desconfianza y, desde luego, incomodidad. En el supuesto de que exista tal idoneidad lo procedente será llamar la atención sobre los datos que llevan a esa conclusión y dejar que el propio interlocutor llegue a ella.

A los Perceptivos les agrada hablar de cuestiones generales y personales antes de entrar en la discusión propiamente profesional. Ello creará un buen ambiente previo y facilitará la interacción posterior.

Al presentar una determinada proposición será conveniente hacer constar que se han tenido en cuenta las implicaciones personales del proyecto: colectivos afectados, posibles reacciones, etc. El apoyo que determinadas personas pueden prestar a las acciones que se sugieren o que se están realizando tiene para ellos una gran importancia.

Asimismo será conveniente apoyar la propuesta en experiencias anteriores que hayan tenido éxito y señalar que en el caso de que se detecten problemas se podrán llevar a cabo los ajustes necesarios para minimizarlos.

En el caso de los Intuitivos habrá que estar dispuesto a dedicar a la discusión todo el tiempo necesario sin impacientarse por las disgresiones que aquéllos puedan hacer.

Las intervenciones podrán ser todo lo extensas que se considere oportuno, pudiendo alcanzarse un alto nivel de abstracción y conceptualización. Deberán estructurarse a partir de ideas-fuerza que sopor- 


\section{LINEAS DE ADAPTACION A LOS ESTILOS}

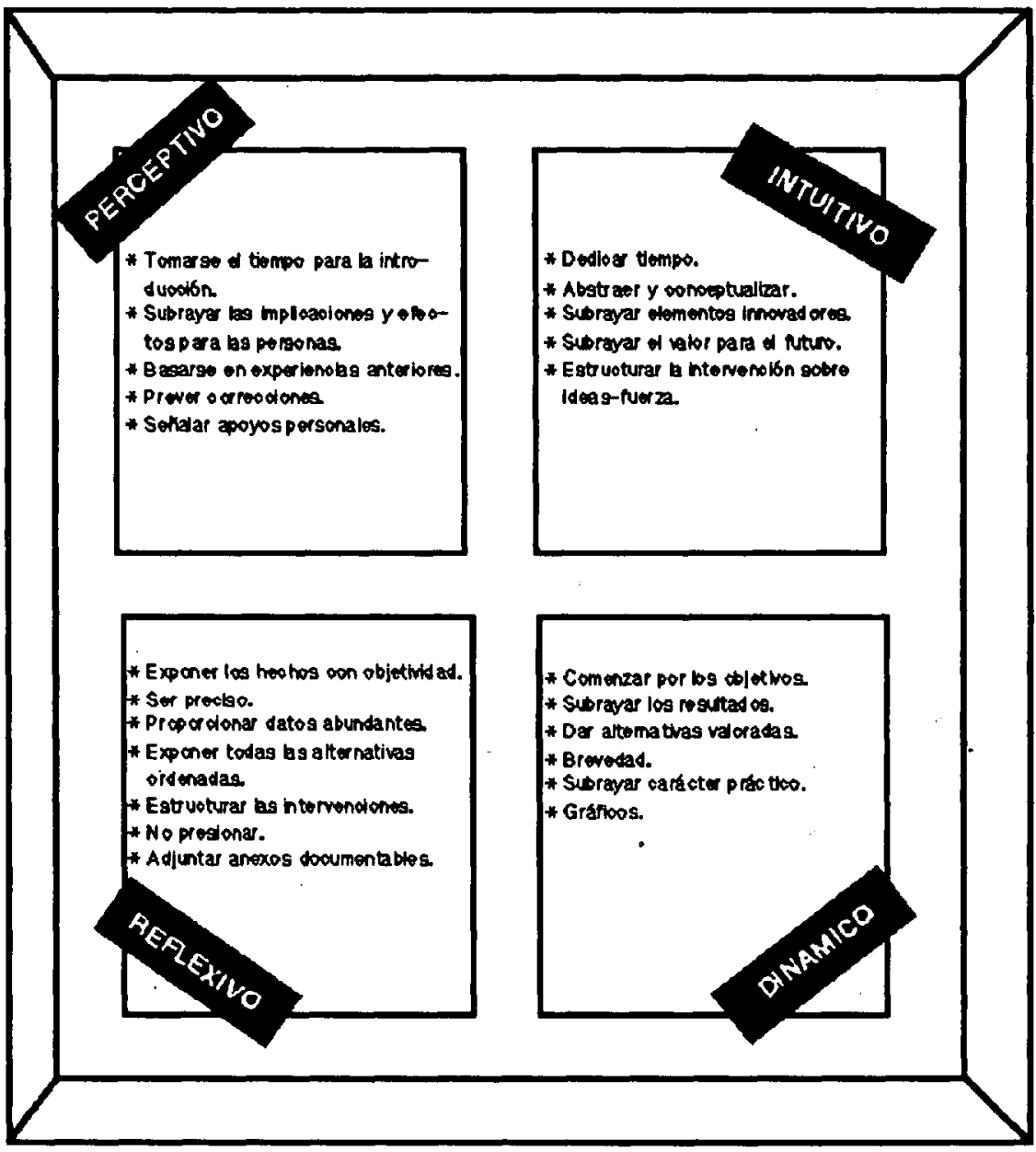

ten el conjunto de las acciones que se proponen y exponerse desde lo general a lo particular y de lo abstracto a lo concreto.

Símpre que ello sea posible será conveniente subrayar el carácter único e innovador del proyecto o de la idea que se presente, así como su valor cara al futuro.

Finalizada ya la exposición de las líneas de adaptación a los otros estilos, con el fin de mejorar el proceso de comunicación, de nuevo hay que volver sobre lo ya dicho en el sentido de que este esfuerzo de adaptación tiene unos límites que habrá que respetar para no situarse en posición de inferioridad por actuar demasiado forzadamente. Así, por ejemplo, un reflexivo, llegado un determinado momento, tendrá 
dificultades para comportarse como su interlocutor dinámico porque correrá el riesgo de sentirse arrastrado a un frenesí hiperactivo, que en gran medida escapará a su control, y, en el supuesto contrario, el dinámico se verá consumido por la impaciencia.

En última instancia se podría decir que si se opta por aplicar esta técnica lo importante es ser uno mismo y actuar con naturalidad, pero esforzándose por comprender el punto de vista de los demás para presentar los hechos y las propuestas de la manera más accesible posible a la mentalidad de nuestros interlocutores y compañeros de equipo con los que tenemos un objetivo común, al tiempo que limamos las aristas más cortantes de nuestro estilo profesional.

De este modo estaremos actuando a semejanza de los músicos de una orquesta (27), en la que cada uno de ellos toca en acorde con el de al lado. Así la comunicación adquirirá la condición de sistema en el que los interlocutores se implican, produciéndose un acuerdo tácito sobre la interacción que acabará integrando los comportamientos individuales, dando paso a la sincronía.

ANÁlisis TRANSACCIONAL

Uno de los problemas más importantes que se producen habitualmente en los equipos se refiere a la comunicación entre sus miembros. Por ello la sicología y sociología en los grupos ha prestado gran atención a esta materia y hoy se dispone de un amplio repertorio de instrumentos que pretenden facilitar dicha comunicación para hacerla más eficaz y menos distorsionada.

Nosotros nos vamos a ocupar a continuación del Análisis Transaccional $(A T)$, precisamente en tanto que instrumento que puede centrarse en los aspectos personales de la comunicación para mejorar sus procesos, especialmente en lo que se refiere a la resolución de problemas profesionales.

El AT es una teoría derivada del Psicoanálisis, elaborada a finales de los sesenta por el psiquíatra Eric BERNe (28) a partir de sus experiencias clínicas.

BERNE observó que sus pacientes ofrecían diferentes estados de la personalidad a lo largo de una misma sesión y que el conocimiento de este hecho le permitía tener una mejor comprensión de sus problemas.

El conjunto teórico y práctico elaborado a partir de esta experiencia y su posterior desarrollo se presenta de una forma muy operativa

(27) A la Escuela de Palo Alto (Bateson, Birdwhistell, Goffman, Hall, Jackson, Scheflen, Sigman y Watzlawick) se debe la metáfora de la orquesta aplicada al terreno de la comunicación.

(28) BERNE, Eric: Analyse transactionnelle et psychothérapie, Payot, París, 1971. 
y accesible, orientada hacia la comprensión y la acción, y resulta aplicable tanto a las personas como a los grupos, al igual que otras técnicas que ya hemos visto (v. gr. liderazgo situacional).

En su conjunto el AT se ordena en cuatro campos teóricos (29):

- El análisis de los estados del Yo: tanto en el aspecto estructural (lo que sucede en el interior de una persona) como en el funcional (funciones desarrolladas por cada una de las partes de nuestro yo).

- El análisis de las transacciones: qué intercambios se producen entre dos personas y cómo sucede.

- El análisis de juegos: cierto tipo de intercambios que conducen a sentimientos negativos.

- El análisis de escenarios: el esquema global de vida, construido y reforzado desde la primera infancia, del que surge la manera de ser y de actuar del presente.

En el marco de este trabajo, a nosotros el AT nos interesa en tanto que instrumento que puede centrarse en los aspectos personales de la comunicación para mejorar sus procesos, especialmente en lo que se refiere a la resolución de problemas. Por ello nos ocuparemos únicamente de los dos primeros aspectos: el análisis de los estados del Yo y el análisis de las transacciones.

En esta línea el AT presenta importantes ventajas sobre otras teorías, como, por ejemplo, no requerir ningún conocimiento ni hipótesis previos acerca de las personas objeto del mismo. La importancia para el AT no radica en cómo se es, sino en cómo se está.

En ese sentido los objetivos que la técnica se plantea son los siguientes:

1. Identificar la posición de nuestro interlocutor.

2. Identificar la posición propia.

3. Evitar mensajes que rompan la comunicación.

$4 .^{\circ}$ Modificar la posición del interlocutor.

Los estados del Yo

En toda personalidad existen tres estados que permiten al individuo reaccionar de forma distinta ante los acontecimientos o ante un mismo suceso, si éste se produce en momentos diferentes. Estos estados vienen determinados: a) por los valores y lo aprendido; $b$ ) por las

(29) Vergnaud, Jean-M., y Buin, Philippe: L'analyse transactionnelle. Outil d'evolution personnelle et professionnelle, Les Editions d'Organisation, París, 1987. 
informaciones de las que se dispone, y $c$ ) por los sentimientos y los deseos.

BERNE denominó y clasificó estos tres estados de siguiente modo (30):

PADRE

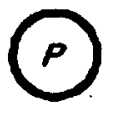

ADULTO

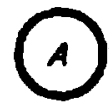

NIÑO

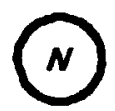

En el Padre reside el mundo normativo: los valores, las reglas, las tradiciones y los juicios. Engloba aquello que cada uno ha copiado de sus mismos padres y de otras figuras que para uno representan la autoridad, enriqueciéndolo con las vivencias propias.

El Adulto representa la objetividad: las informaciones tomadas de la realidad. En él reside la capacidad para recoger, almacenar y tratar la información procedente de los otros estados del Yo y del exterior. El Adulto es quien decide de forma objetiva, sin dejarse condicionar por emociones ni prejuicios, qué estado del Yo es conveniente utilizar en cada momento. Se le compara por ello con un ordenador.

El Niño es la afectividad: recoge el conjunto de los deseos y emociones del individuo, sean éstas espontáneas o condicionadas. Es el primero de los estados del Yo en que comienza a estructurarse la personalidad y el último en desaparecer, considerándose como un resto de la etapa infantil que perdura en la edad adulta.

De acuerdo con lo anterior, ante un mismo hecho o problema una persona puede reaccionar como Padre, como Adulto o como Niño. Supongamos que en una Dirección General de Servicios se ha producido una avería importante en el sistema informático que va a imposibilitar que la nómina de todo el Departamento se haga efectiva a final de mes. Ante este problema caben diferentes reacciones, algunas de las cuales podrían ordenarse del siguiente modo:

(30) Una representación gráfica y sinóptica muy útil del AT puede encontrarse en VERG. NAUD y BLIN, op. cit., pp. 6 y ss. También lo tratan con cierta extensión, aplicada al mundo de la empresa, BLANCO, Adolfo, y SENLLE, Andrés: Desarrollo de directivos y calidad total en la organización, ESIC Editorial, Madrid, 1988. 


\section{Padre:}

a) «Esto es inadmisible y sucede porque no respetan las normas de seguridad en el sentido de tener soluciones alternativas. Se van a enterar.»

b) «No es la primera vez que pasa esto, pero tiene que ser la última. En el fondo no son mala gente, pero hay que estar encima de ellos para que funcionen.»

\section{Adulto:}

«Hay que llamar a la casa que preparó la aplicación, para que vengan en seguida, vean qué pasa y lo arreglen.»

\section{Niño:}

« ¿Uf! Pues nos vamos a divertir, veréis la bronca que se va a armar cuando la gente se entere de que no cobra.»

De estas alternativas parece evidente que la posición inicial más apropiada para resolver el problema es la de Adulto. Por tanto, en el trabajo en equipo nuestro objetivo debe ser situarnos en estado Adulto y conseguir que nuestros interlocutores hagan lo mismo para ser más productivos globalmente.

Sin embargo, esto no quiere decir que el estado más indicado sea siempre el de Adulto. En ocasiones puede ser más rentable tener otra posición o al menos partir de ella. Así sucede, por ejemplo, cuando es preciso corregir a un colaborador por un trabajo mal hecho sin causa aparente que lo justifique o cuando se trata de ejercer una comunicación persuasiva con ocasión de un curso de formación. En estos supuestos podrá ser más eficaz el estado de Padre. Por el contrario, a lo largo de una reunión que requiera mucha concentración puede resultar conveniente a la hora del descanso manifestarse desde el estado Niño, porque ello facilitará la relación y actuará como relajante de la tensión acumulada.

\section{Análisis funcional}

Esto nos lleva a lo que inicialmente hemos llamado el análisis funcional de los estados del Yo, atendiendo a las funciones que realizan.

Según este criterio el Padre se subdivide en otros dos estados: el Padre Crítico y el Padre Nutricio. El primero se caracteriza por emitir juicios de valor y vigilar que se respeten las normas establecidas; su actuación es positiva cuando, en función de lo anterior, garantiza la supervivencia del grupo, y negativa cuando impone su criterio y abusa de la autoridad de que dispone. Al segundo le corresponde ser com- 
prensivo con las demás personas y tomar a su cargo la solución de los conflictos; es eficaz cuando consuela, comprende y da apoyo, pero resulta negativo cuando actúa de forma absorbente y anula las iniciativas de los demás.

Por su parte, el Niño, que BERNE consideraba el estado más rico, se divide básicamente en Niño Adaptado y en Niño Natural. En el primer caso actuará condicionado de forma refleja por las directrices del Padre; puede ser positivo, si autocensura una actuación incorrecta, o negativo, si impide el ejercicio de la creatividad. En el segundo se manifestará de forma autónoma, sin censura alguna, según sus propios deseos, resultando positivo por sus aportaciones innovadoras o negativo si no se somete a ninguna regla, y será percibido entonces como disfuncional.

PADRE

ADULTO

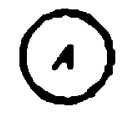

NINOO

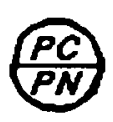

A

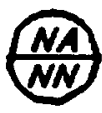

PADRE CRITICO

PADRE NUTRICIO

ADULTO
NIÑO ADAPTADO

NINOO NATURAL

Ahora ya estamos en posesión de los elementos básicos del AT. La cuestión es, llegados a este punto, cómo utilizarlo para mejorar nuestro comportamiento y el de nuestros colaboradores en orden a un mayor rendimiento del equipo.

Recordemos que inicialmente nos planteábamos la utilidad del AT como técnica para mejorar la comunicación en la resolución de problemas. Por ello el primer paso consiste, como dijimos al enumerar los objetivos o fases de la técnica, en saber reconocer el estado del Yo en que nos encontramos nosotros mismos en un momento dado y en identificar el estado de nuestro interlocutor. Ambos objetivos no son fáciles de alcanzar y el primero de ellos exije un notable ejercicio de sinceridad con nosotros mismos.

$\mathrm{Si}$ ante nuestro interlocutor descubrimos que los sentimientos que nos dominan son los de crítica, censura, paternalismo o comprensión, en cualquiera de sus variantes, nos encontramos en estado Padre. 
Continuar con el ejemplo de los problemas en la confección de la nómina que veíamos antes nos puede resultar de utilidad si imaginamos que somos el Director general de Servicios que, tras conocer el incidente, está despachando con el Subdirector responsable del CPD:

DG: «Rodolfo, esto es inadmisible. Ya es la tercera vez que sucede desde que estoy en este Ministerio. A ver cómo le explico yo en esta ocasión a Juan Antonio, el Subsecretario, que no voy a poder pagar la nómina a tiempo.»

Es evidente que nos encontramos en estado Padre y, además, Crítico. En esta situación nos domina el enfado y nos resulta difícil analizar los hechos con objetividad. Estamos preocupados por cómo justificarnos personalmente ante el Subsecretario y no por cómo solucionar el problema lo más rápidamente posible. Es decir, estamos perdiendo tiempo.

Otra posibilidad es la siguiente:

DG: «Oye, ¿pero qué ha pasado en esta ocasión? ¿Qué le pasa a ese ordenador que se cae tantas veces? ¿Has llamado ya a los de la empresa de mantenimiento? Tenemos que hacer algo para que no suceda más veces.»

En este caso nos hallaremos en estado Adulto, recopilando información para tomar una decisión correctora, tras averiguar qué ha sucedido y si se ha llevado ya a cabo alguna actuación. De momento estamos prescindiendo de nuestros sentimientos, o dominándolos, para concentrarnos en lo más importante: solucionar el problema.

Finalmente, cabe la posibilidad de que ante la situación existente nos dominen las emociones o los deseos. En ese caso responderíamos desde el estado Niño, que se deja llevar por su deseo de placer y no asume su responsabilidad:

DG: « $¡$ Vaya problema que se nos ha planteado! Habría que ver qué hacemos, pero la verdad es que siendo viernes y con este calor cualquiera se pone a ello. Mira, yo esta tarde no vengo porque he quedado con unos amigos a comer en la piscina y a jugar al ajedrez; el lunes a primera hora lo estudiamos con tranquilidad.»

Por otra parte, es preciso que identifiquemos el estado de la persona con la que estamos en interacción. Para ello debemos utilizar los mismos criterios que hemos seguido para reconocer nuestro estado, pero además debemos atender al significado de la comunicación no ver- 
bal: determinados gestos, posiciones del cuerpo o el tono de voz pueden resultar enormemente reveladores y contener un mensaje diferente al que se nos está enviando a través de la palabra, con lo que podremos descubrir el auténtico estado del Yo de nuestro interlocutor, mejorando así nuestras posibilidades de actuación.

Veamos ahora algunos de los posibles comportamientos del Subdirector responsable de la edición informatizada de la nómina, en la conversación con su Director:

SG: «iHombre, Paco, tampoco te pongas así conmigo! Ya en alguna ocasión te he dicho que el hardware que tenemos no dispone de suficiente capacidad para todas las aplicaciones que soporta y tú no has querido saber nada. Que sólo te acuerdas de Santa Bárbara cuando truena.»

Aquí el Subdirector se ha sentido injustamente agredido por un $\mathrm{Pa}$ dre Crítico y reacciona también desde el estado de Padre Crítico, censurando a su jefe por no haber tomado en serio sus advertencias. Es ésta una mala situación porque lo más probable es que la discusión se mantenga con un encadenamiento de reproches mutuos que deteriorarán la relación y no permitirán abordar el problema de fondo en las condiciones adecuadas de objetividad.

Otra posibilidad es que el Subdirector general reaccione en estado Adulto, preocupado exclusivamente por solucionar el problema:

SG: «Tras los otros fallos que tuvimos ya lo sospechábamos, pero ahora hemos comprobado que el origen del problema radica en la falta de capacidad del sistema para soportar todas las aplicaciones operando al mismo tiempo. Están ya aquí los de la casa proveedora y creen que a última hora de hoy podrán dar una solución provisional, mientras preparan la definitiva.»

Como ya hemos repetido, éste es el mejor estado tanto para negociar como para solucionar el problema. Claro que ello exige que el interlocutor esté también en estado Adulto, ya que si no, según cual sea su estado, se estarán frustrando sus expectativas al recibir mensajes emitidos por un estado diferente al que él espera que le conteste. Esto sucederá, por ejemplo, si el mensaje ha sido emitido por el Director general como Padre Crítico.

En este último caso, el conflicto se agudizará aún más si la respuesta del Subdirector se produce en los términos siguientes: 
SG: "Venga hombre, no te pongas así, que no es para tanto. Al fin' y al cabo ya ha sucedido otras veces y la gente se aguanta. El lunes cuando volvamos al trabajo lo miraremos y ya veremos qué se puede hacer.»

Aquí el conflicto está garantizado entre un Padre Crítico y un Niño Natural, que es quien ha contestado al primero.

\section{Las transacciones}

Todo este proceso, una vez que se es capaz de identificar el estado del Yo en el que se encuentra nuestro interlocutor y en el que nos hallamos nosotros mismos, nos conduce al análisis de las transacciones con el fin de evitar las comunicaciones cruzadas y con el objetivo de llevar a nuestro interlocutor al estado de Adulto o de evolucionar nosotros hacia dicho estado.

Como ya hemos adelantado, una de las reglas básicas del AT es evitar este tipo de transacción cruzada, que se produce cuando se responde desde un estado distinto al que se dirigía el mensaje, originando una frustración semejante a la que se ocasiona cuando nos dirijimos a una persona y nos contesta otra. Por ello, la técnica del AT consiste en responder a nuestro interlocutor desde el estado al que él se ha dirigido para, a continuación, intentar la transición hacia el estado Adulto.

De cómo conseguir esto nos ocupamos a continuación.

Cuando habla un Padre espera que le responda otro Padre que confirme su crítica o un Niño que se la acepte o que requiera su comprensión y apoyo. Si el que emite es un Adulto, lógicamente espera que le responda otro Adulto con el que mantener una relación fundada en la objetividad. Y si el que emite es un Niño deseará la respuesta de otro Niño o la de un Padre que le dé apoyo, consejo o comprensión.

El resto de las transacciones o son fracamente negativas o son potencialmente problemáticas.

Supongamos que la relación está teniendo lugar entre el Director y el Subdirector que conocemos. Si ambos están en estado Adulto (recordemos la conversación) esa disposición debe mantenerse, ya que aunque no es garantía de éxito al menos es la que menos problemas plantea y la que se considera más productiva.

Pero imaginemos que el que está emitiendo el primer mensaje es el Padre Crítico. El espera que le conteste un Niño Adaptado, que acepte la censura y que esté dispuesto a cumplir sus órdenes. Si esto no es así y le responde un Adulto, frío y objetivo, que no acepta expresamente la censura formulada, o un Niño Natural, que no asume 
EMISOR

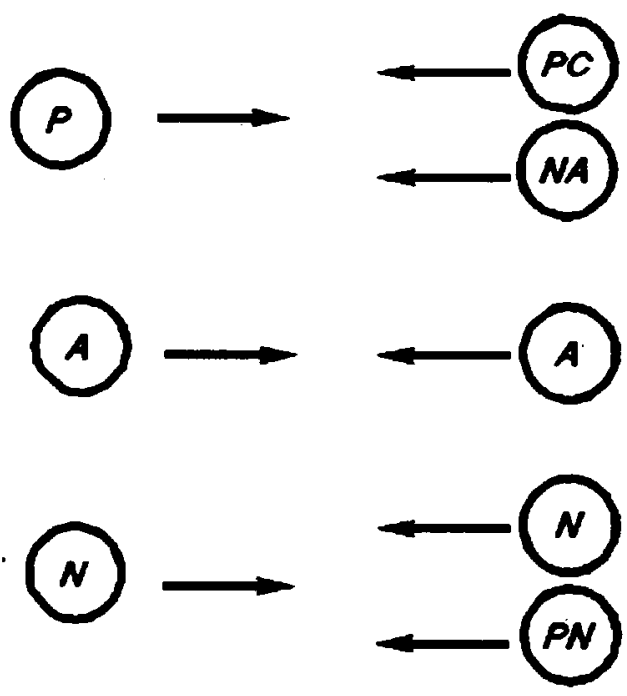

el problema ni da muestras de corrección, estaremos ante transacciones cruzadas que deteriorarán cada vez más la relación conduciendo, probablemente, a un mal final.

Será recomendable, colocándonos en el lugar del Subdirector, un comportamiento parecido a éste:

SG: «La verdad es que no sé cómo justificarme, Paco. Todas las semanas al hacer mi programación incluyo el ocuparme de dar solución al problema de las nóminas, pero una y otra vez surge un asunto urgente e imprevisto que me lo impide. La verdad es que lo siento, sobre todo por ti que me lo habías dicho. Pero dile al Subse que ya estoy en ello para que el retraso sea mínimo, si es que lo hay. Precisamente acabo de hablar con la casa, que me ha comentado...»

Con esta actitud se ha respondido al Padre Crítico como Niño Adaptado para aplacarle y posteriormente se le han ido enviando mensajes constructivos para «bajarle» a la posición de Adulto y poder hablar en términos objetivos.

Otra posibilidad es que el propio Director estuviera en estado Niño, como ya vimos y no quisiera hacer frente al problema. En este caso, la actitud del Subdirector inicialmente no puede ser la de Padre Crítico que censure la falta de responsabilidad de su superior, ya que está 
dentro de lo probable que ante ello el Director, herido, reaccione a su vez como Padre Crítico ejerciendo toda su autoridad y bloqueándose la posibilidad de una relación constructiva. Mejor sería responder como Niño al que le gustaría dejar el trabajo para otro momento, para luego hacer una transición suave hacia el estado Adulto mediante una alusión discreta a la responsabilidad propia que haga que se manifieste el estado Adulto del Yo del Director.

\section{Comportamiento profesional}

Para finalizar nos referiremos, muy esquemáticamente, a algunos de los rasgos del comportamiento de los estados del Yo en su actuación profesional (31):

Padre Crítico: Utiliza a fondo su autoridad. No admite que se discutan sus órdenes. Obsesionado por las normas, a veces esto le hace perder eficacia. Más orientado hacia la tarea que hacia la relación.

Toma las decisiones rápidamente, pues considera que tiene muy claro lo que hay que hacer.

Padre Nutricio: Tiene buena imagen entre sus subordinados, ya que, por su orientación a la relación, es muy comprensivo con los fallos. Compensa lo anterior con un sentido de la responsabilidad que le lleva a ser él quien busque la solución.

Le resulta difícil tomar decisiones tajantes, pero las asume posteriormente, igual que los riesgos.

Adulto: $\quad$ Si está técnicamente preparado, sus instrucciones son claras, y si integra correctamente su propio PAN cuida tanto la orientación a la tarea como a la relación. Su eficacia dependerá del estado de su equipo.

En la toma de decisiones actúa con rapidez si dispone de los datos necesarios, en caso contratio opta por demorarla hasta disponer de ellos.

Niño Adaptado: No le atrae el protagonismo, que prefiere dejar a sus superiores, y busca el consenso con sus subordinados. $\mathrm{Al}$ tomar decisiones le preocupa actuar dentro de las reglas y, por lo mismo, se inspira en el precedente para la resolución de problemas.

(31) VeRNAUD y Blin: op. cit., pp. 12 y 13. 
Niño Natural: Puede dinamizar a sus compañeros, pero su tendencia innata hacia el desorden no le permite dirigirlos adecuadamente.

Puede adoptar decisiones muy acertadas ante lo inesperado y a corto plazo, pero se enfrenta mal a la planificación.

Ante los problemas reacciona emocionalmente si revisten dificultades.

El Análisis Transaccional es mucho más complicado que lo que acabamos de ver. Pero su concepción práctica y la claridad de sus elementos permiten realizar una aplicación del mismo que complete la «actuación intuitiva» que en ocasiones llevamos a cabo ante los conflictos y los problemas de la comunicación.

Tampoco se puede decir que su utilización garantice el éxito en todas las ocasiones, pero sí es cierto que puede proporcionarnos un cierto dominio de nuestro comportamiento y un conocimiento mejor del comportamiento ajeno, lo que nos sitúa en condiciones ventajosas para minimizar las tensiones y potenciar las relaciones productivas, que al fin y al cabo es lo que pretendemos cuando nos integramos en un equipo o lo dirigimos. 
DA-1990, núm. 223. JAVIER VALERO IGLESIAS. El trabajo en equipo

DA-1990, núm. 223. JAVIER VALERO IGLESIAS. El trabajo en equipo 